\title{
Climatic regions as an indicator of forest coarse and fine woody debris carbon stocks in the United States Christopher W Woodall* and Greg C Liknes
}

\author{
Address: USDA Forest Service, Northern Research Station, 1992 Folwell Avenue, St. Paul, MN 55108, USA \\ Email: Christopher W Woodall* - cwoodall@fs.fed.us; Greg C Liknes - gliknes@fs.fed.us \\ * Corresponding author
}

Published: 9 June 2008

Carbon Balance and Management 2008, 3:5 doi:10.1186/1750-0680-3-5

This article is available from: http://www.cbmjournal.com/content/3/I/5

(C) 2008 Woodall and Liknes; licensee BioMed Central Ltd.

This is an Open Access article distributed under the terms of the Creative Commons Attribution License (http://creativecommons.org/licenses/by/2.0), which permits unrestricted use, distribution, and reproduction in any medium, provided the original work is properly cited.
Received: 28 March 2008

Accepted: 9 June 2008

\begin{abstract}
Background: Coarse and fine woody debris are substantial forest ecosystem carbon stocks; however, there is a lack of understanding how these detrital carbon stocks vary across forested landscapes. Because forest woody detritus production and decay rates may partially depend on climatic conditions, the accumulation of coarse and fine woody debris carbon stocks in forests may be correlated with climate. This study used a nationwide inventory of coarse and fine woody debris in the United States to examine how these carbon stocks vary by climatic regions and variables.

Results: Mean coarse and fine woody debris forest carbon stocks vary by Köppen's climatic regions across the United States. The highest carbon stocks were found in regions with cool summers while the lowest carbon stocks were found in arid desert/steppes or temperate humid regions. Coarse and fine woody debris carbon stocks were found to be positively correlated with available moisture and negatively correlated with maximum temperature.

Conclusion: It was concluded with only medium confidence that coarse and fine woody debris carbon stocks may be at risk of becoming net emitter of carbon under a global climate warming scenario as increases in coarse or fine woody debris production (sinks) may be more than offset by increases in forest woody detritus decay rates (emission). Given the preliminary results of this study and the rather tenuous status of coarse and fine woody debris carbon stocks as either a source or sink of $\mathrm{CO}_{2}$, further research is suggested in the areas of forest detritus decay and production.
\end{abstract}

\section{Background}

Estimation of carbon sequestration using large-scale forest inventory data has become important due to the link between possible climate change and the accumulation of greenhouse gases in the atmosphere [1,2]. In 1992, 150 countries including the U.S. signed the United Nations Framework Convention on Climate Change that resulted in the development of annual reports of greenhouse gas inventories including carbon in forests. Forest carbon pools are often delineated as standing live trees, standing dead trees, down and dead woody materials, forest floor, understory, and soils. The down and dead woody materials pool (detritus) essentially consists of coarse woody debris, fine woody debris, and stumps. Coarse woody debris is defined by the Forest Inventory and Analysis (FIA) program of the USDA Forest Service as down and dead woody material at least $7.62 \mathrm{~cm}$ in diameter [3]. Fine woody debris is defined by FIA as dead and down woody material with a diameter between 0.01 and $7.61 \mathrm{~cm} \mathrm{[3].} \mathrm{In}$ the U.S., it has been estimated that $35 \%$ of the total forest 
carbon pool is in live vegetation, $52 \%$ is in the soil, and $14 \%$ is in dead organic material [4]. Therefore, estimating coarse and fine woody debris carbon stocks across the United States is crucial to national carbon reporting and monitoring.

Forest terrestrial carbon sinks represent a fine balance between the influx of $\mathrm{CO}_{2}$ into photosynthesis and the efflux of $\mathrm{CO}_{2}$ through woody decay processes [1]. The decay rate of any individual piece of forest dead wood is determined by substrate quality, microbial activity, air temperature, and available moisture [5]. Similarly, the productive capacity of any given forest is partially governed by climatic variables such as temperature [6]. Some studies have suggested that forest detritus production and decay may be in balance [7], whereas others have suggested increased detritus decomposition rates may ultimately cause forest detritus carbon pools to become net $\mathrm{CO}_{2}$ emitters [8,9]. Quantifying the dynamics of forest detritus carbon accumulation and turnover within a scenario of global climate warming is critical to predicting the future inventory of United States carbon stocks. Indeed, some studies have already indicated the effects that changing climate can have on the terrestrial carbon cycle [10] and highlighted the possibility of increasing emission of $\mathrm{CO} 2$ from non-live forest carbon pools such as soils [11]. Emerging suggestions to bury coarse woody debris as a cost effective carbon sequestration technique [12] would be impacted if coarse woody decay rates are increased by changing climate. To date, initial investigations of coarse and fine woody debris carbon stocks across classes of latitude have indicated that these carbon stocks may be related to climatic variables [13]. Therefore, correlating coarse and fine woody debris carbon stocks with climatic regions and variables across the United States is highly warranted.

The goal of this study is to relate forest coarse and fine woody debris carbon stocks to climatic regions and variables across the United States with specific objectives including: 1) to estimate mean coarse woody debris, fine woody debris, and total woody detritus carbon stocks (coarse + fine woody debris) by Köppen climatic regions, 2) to correlate/model coarse woody debris, fine woody debris, and total woody detritus carbon stocks with individual climatic variables (average annual precipitation (PRECIP), mean annual maximum temperature (TMAX), mean annual minimum temperature (TMIN), moisture index (MOIST), variability cause (VAR), and potential evapotranspiration (EVAP)), and 3) to interpret the results of this study in the context of possible climate change.

\section{Results}

Coarse and fine woody debris carbon stocks vary by climatic region with the largest mean stocks found in dry/ cool climates such as "warm temperate with dry summer (Cs)" and "snow, fully humid, cool summer (Dfc)" where decay rates may be reduced (Table 1). Forest ecosystems associated with these climatic regions are chaparral, northern Rockies, and extreme northern boreal. Climatic regions with the lowest mean coarse and fine woody debris carbon stocks were dry/hot climates such as "arid desert (BW)" or "warm temperate, fully humid (Cf)." Forest ecosystems associated with these climatic zones are southwestern deserts and steppes or southeastern mixed forests. When displayed spatially, climatic regions that are cooler (i.e. higher latitudes or higher elevation) tend to have higher downed and dead wood forest carbon stocks (Fig. 1). ANOVA's indicated significant differences between the carbon stock means among climatic regions (p-value $<0.0001$ ).

When correlated with a host of individual climatic variables, coarse and fine woody debris carbon stocks were found to be positively correlated with PRECIP and MOIST. In contrast, coarse and fine woody debris were negatively correlated with TMAX, TMIN, VAR, and EVAP (Table 2). In terms of total down woody carbon, the strongest correlations were with MOIST (cor. coeff. = 0.36 ) and TMAX (cor. coeff. = -0.30). Fine woody debris carbon stocks had weaker correlations with climatic varia-

Table I: Means and associated standard errors for forest coarse woody debris (CWD), fine woody debris (FWD), and total down woody carbon (C) stocks (tonnes ha^$^{\wedge}-$ I) for Köppen's climatic regions/subgroups across the United States

\begin{tabular}{|c|c|c|c|c|c|c|c|}
\hline Climatic region & $\mathrm{n}$ & Mean CWD carbon (tonnes $\mathrm{ha}^{\wedge}-\mathrm{I}$ ) & Std err. & Mean FWD carbon (tonnes ha^ ${ }^{\wedge}-1$ ) & Std err. & Mean total down woody $C$ (tonnes ha $\left.{ }^{\wedge}-1\right)$ & Std err. \\
\hline BS & 591 & 0.47 & 0.07 & 0.89 & 0.10 & 1.36 & 0.13 \\
\hline BW & 109 & 0.00 & 0.00 & 0.08 & 0.06 & 0.09 & 0.06 \\
\hline Cs & 583 & 5.21 & 0.36 & 2.57 & 0.14 & 7.78 & 0.43 \\
\hline $\mathrm{Cf}$ & 1835 & 2.24 & 0.11 & 2.94 & 0.07 & 5.18 & 0.14 \\
\hline Ds & 609 & 5.70 & 0.34 & 2.59 & 0.12 & 8.29 & 0.41 \\
\hline Dw & 9 & 4.05 & 1.36 & 1.29 & 0.64 & 5.33 & 1.71 \\
\hline Dfa & 676 & 3.43 & 0.21 & 3.16 & 0.12 & 6.59 & 0.27 \\
\hline Dfb & 1494 & 4.27 & 0.15 & 3.43 & 0.09 & 7.69 & 0.18 \\
\hline$D f c$ & 188 & 7.11 & 0.55 & 2.62 & 0.17 & 9.73 & 0.59 \\
\hline $\mathrm{H}$ & 9 & 3.78 & 1.84 & 3.85 & $\mathrm{I} .44$ & 7.63 & 2.41 \\
\hline
\end{tabular}




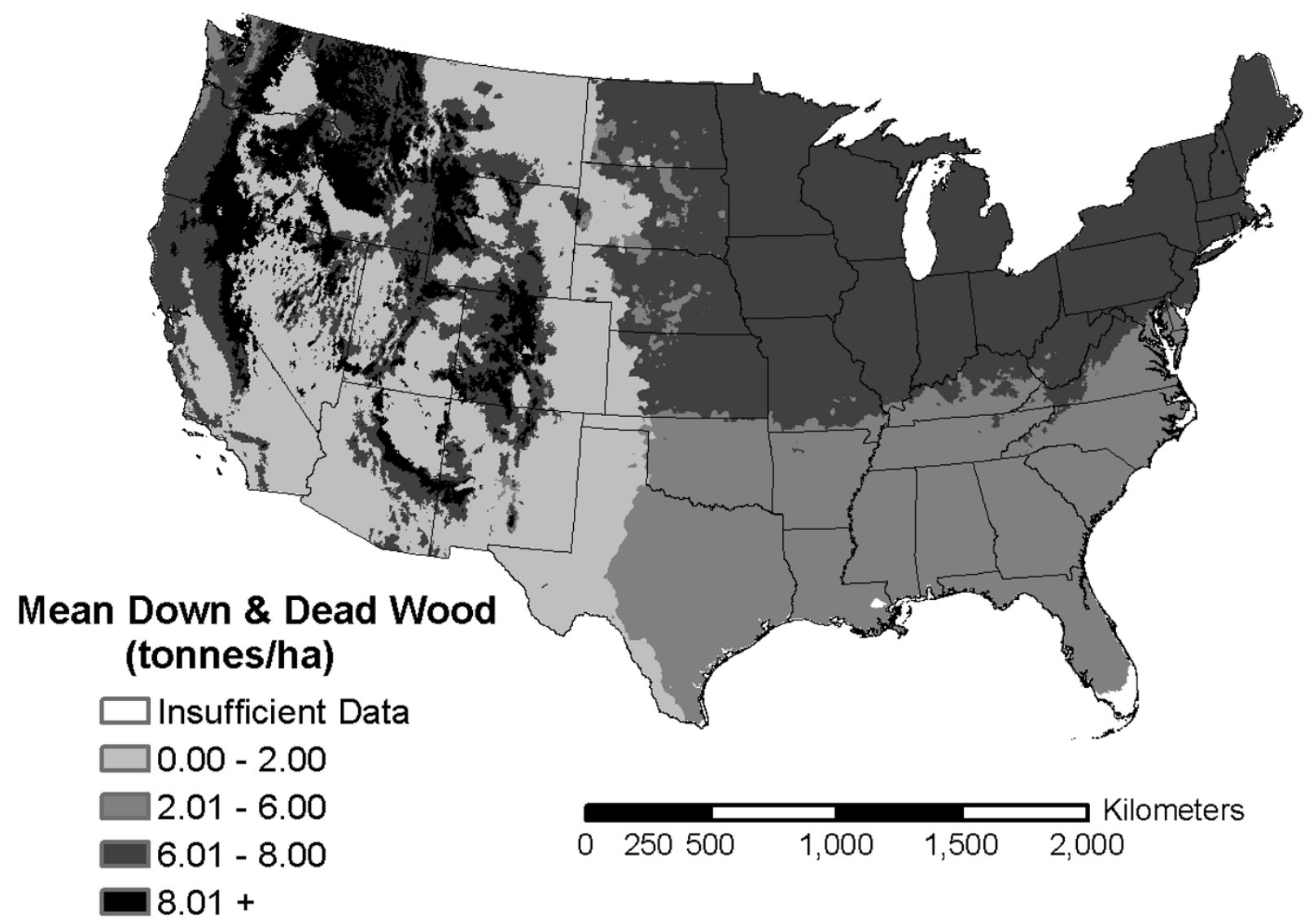

Figure I

Continental U.S. Köppen climatic regions shaded by classes of mean total down woody $\mathrm{C}$ stocks.

bles when compared to coarse woody debris carbon stock and climatic correlations.

Linear regressions between total woody detritus stocks and TMAX and PRECIP indicated tremendous data scatter along with very weak R-square's $(<0.1)$ (RMSE TMAX model = 7.386; RMSE PRECIP model = 7.529) (Figs. 2, 3). Total woody detritus stocks had a negative relationship with increasing TMAX. In comparison, total woody detritus stocks had a barely positive relationship with increas-

Table 2: Pearson's correlations coefficients and associated p-values for forest coarse woody debris (CWD), fine woody debris (FWD), and total down woody carbon (C) stocks by climatic attributes

\begin{tabular}{|c|c|c|c|c|c|c|}
\hline \multirow[t]{2}{*}{ Climate variables } & \multicolumn{2}{|c|}{ Coarse woody debris $C$} & \multicolumn{2}{|c|}{ Fine woody debris $C$} & \multicolumn{2}{|c|}{ Total down woody $C$} \\
\hline & Corr. coeff. & $\mathrm{p}$-value & Corr. coeff. & $\mathrm{p}$-value & Corr. coeff. & $\mathrm{p}$-value \\
\hline PRECIP & 0.25 & $<0.001$ & 0.22 & $<0.001$ & 0.29 & $<0.001$ \\
\hline TMAX & -0.30 & $<0.001$ & -0.13 & $<0.001$ & -0.30 & $<0.001$ \\
\hline TMIN & -0.24 & $<0.001$ & -0.07 & $<0.001$ & -0.22 & $<0.001$ \\
\hline MOIST & 0.29 & $<0.001$ & 0.29 & $<0.001$ & 0.36 & $<0.001$ \\
\hline VAR & -0.19 & $<0.001$ & -0.10 & $<0.001$ & -0.19 & $<0.001$ \\
\hline EVAP & -0.25 & $<0.001$ & -0.06 & $<0.001$ & -0.23 & $<0.001$ \\
\hline
\end{tabular}

: 30-year mean annual yearly precipitation (PRECIP), 30-year mean daily maximum temperature (TMAX), 30-year mean daily minimum temperature (TMIN), moisture index (MOIST), variability cause (VAR), and potential evapotranspiration (EVAP) 


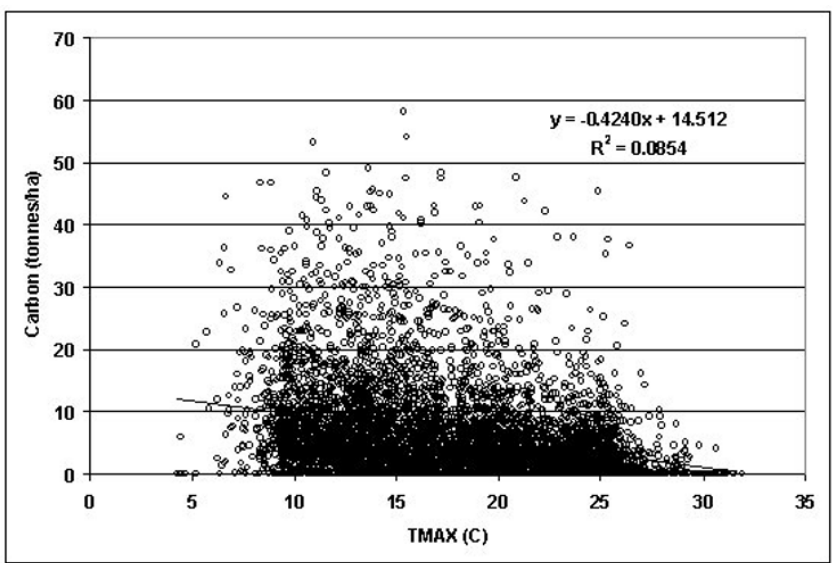

Figure 2

Total down woody $\mathrm{C}$ stocks by 30 -year mean daily maximum temperature (TMAX) (PRISM Group, 2004).

ing PRECIP. Given that the TMAX and PRECIP variables had some of the stronger correlations with woody detritus carbon stocks, regressions conducted between all remaining dependant dead wood carbon stock variables and independent climatic variables demonstrated very weak relationships and did not contribute beyond correlation results.

\section{Discussion}

This study found that coarse and fine woody debris carbon stocks varied by climatic regions and variables. However, these results were relatively weak and may be partially confounded by the varying levels of decay resistance across the range of tree species in the United States $[14,15]$. Therefore, the results of this study provide very limited inference potential at small scales (e.g. states), but

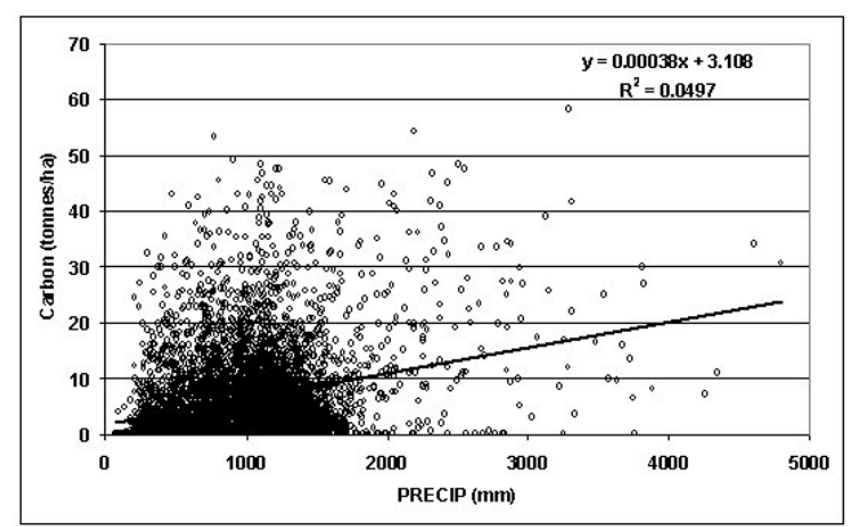

\section{Figure 3}

Total down woody $C$ stocks by 30 -year mean annual precipitation (PRECIP) (PRISM Group, 2004). may help elucidate the dynamics between coarse/fine woody debris carbon stocks and climate at the continental scale. Forest woody detritus carbon stocks are found in the largest amounts in climates that are moist enough to support productive forests while at the same time are cool enough to reduce decay rates. This hypothesis was evidenced by the "snow, fully humid, cool summer" climatic region (Dfc) having the highest mean total dead and downed wood carbon stock of 9.73 tonnes ha^ ${ }^{\wedge} 1$. The climatic region with the lowest mean forest dead and downed wood carbon stock was that of "arid desert" (BW) where the hot temperatures increase decay rates and the lack of moisture reduces forest productivity. These results are similar to those found at smaller scales [9,16-18].

Coarse and fine woody debris carbon stocks vary individually with climatic regions/variables. The cool, moist climatic regions of the Pacific Northwest and high elevations in the Rocky Mountains have the greatest disparity between coarse and fine woody debris carbon stocks with coarse woody debris stocks exceeding fine woody debris stocks by 4.45 tonnes $\mathrm{ha}^{\wedge}-1$ on average. In contrast, the humid and hot climatic regions in the southeastern United States had fine woody debris carbon stocks exceeding coarse woody debris stocks by 0.70 tonnes ha ${ }^{\wedge}-1$ on average. Furthermore, fine woody debris carbon stocks were less correlated with climatic variables than coarse woody debris carbon stocks. Given the ephemeral nature of fine woody debris carbon stocks with their rapid decay and turnover, it is proposed that fine woody debris carbon stocks may be relatively unaffected by increases in global temperature. Studies at smaller scales proposed that forest litter carbon stocks were unaffected by changes in temperature $[1,7,19,20]$. Future fine woody debris carbon stocks may be more affected by tree species shifts than climate shifts [20], an indirect effect of global climate change.

The relationship between temperature, moisture, and forest woody detritus carbon stocks is complicated and not easily summarized [15]. Increases in temperatures and/or moisture are required for increases in forest productivity and subsequent forest detritus accumulation. However, increased temperatures and moisture increase decay rates. Therefore, the climatic variables that increase forest woody detritus production also increase forest detritus decay. Additionally, forest woody detritus resistance to decay is tree species-specific [15], and tree species spatial distributions are partially dependent on climate in the United States [21]. Finally, differences in stand age, disturbance events, and silvicultural practices may confound analyses. Some studies have found forest attributes such as management practices and disturbance history to have an effect on coarse and fine woody debris biomass at small scales $[22,23]$ while others have found little correlation between these variables and woody detritus at large- 
scales $[24,25]$ such as examined in this study. Caveats aside, this study found that forest woody detritus carbon stocks were almost equally correlated with maximum temperature and moisture in opposing directions. This study supports the hypothesis proposed by other studies $[1,7-9,16,26]$ that there is a fine balance for some carbon pools (e.g. forest detritus and soils) as a net $\mathrm{CO}_{2}$ source or sink, all partially dependent on climate and feedback mechanisms.

Based on this study's results, a few conjectures may be postulated. Under a global warming scenario, forest woody detritus carbon stocks might experience accelerated decay/turnover becoming a net $\mathrm{CO}_{2}$ source unless there are concomitant increases in climatic variables favorable to forest productivity (e.g. increased moisture) or reduced detritus decay (e.g. increased $\mathrm{CO}_{2}$; see [5]). Forest woody detritus carbon stocks may be similar in nature to northern peatland soil carbon stocks, at risk to accelerated rates of decay and net $\mathrm{CO}_{2}$ emission as global temperatures increase [27]. Overall, given the uncertainty in predicting future precipitation and management/mortality events, it can only be conjectured that forest woody detritus carbon stocks may face increased risk of becoming a $\mathrm{CO}_{2}$ emitter if temperatures increase $[1,8]$.

\section{Conclusion}

The results of this study established an initial link between forest coarse/fine woody debris carbon stocks and climatic regions/variables. Although this study found the relationships between these carbon stocks and climate to be only moderately evident, we propose that carbon sequestration by forest detritus may be increased by increased moisture availability and reduced by warmer temperatures. A delicate balance may exist where slight changes in climate could change a region's forest woody detritus status as a either a net $\mathrm{CO}_{2}$ source or sink. We further conjecture that under a scenario of global warming, forest woody detritus carbon stocks (especially coarse woody debris) will be at risk for becoming net $\mathrm{CO}_{2}$ emitters. Given the uncertainty found with all relationships identified in this study, further analysis of this study's data [28] may delineate the influence of the factors (e.g., forest management practices) that probably obscure widely recognized effects of temperature and precipitation on regional/local woody detritus carbon stocks.

\section{Methods}

\section{CWD and FWD inventory field methods in the U.S}

The FIA program, the only congressionally mandated national inventory of U.S. forests, conducts a 3-phase inventory of forest attributes of the country [29]. The FIA sampling design is based on a tessellation of the United States into hexagons approximately 2,428 ha in size with at least one permanent plot established in each hexagon.
In phase 1 , the population of interest (forest cover) is stratified and plots are assigned to strata to increase the precision of estimates. In phase 2, tree and site attributes are measured for forested plots established in the 2,428ha hexagons. Phase 2 plots consist of four 7.32-m fixedradius subplots on which standing trees are inventoried.

In phase 3 , a $1 / 16$ subset of phase 2 plots are measured for coarse and fine woody debris on transects radiating from each FIA subplot center [3]. As defined by FIA, coarse woody debris are down logs with a diameter $\geq 7.62 \mathrm{~cm}$ along a length $\geq 0.91 \mathrm{~m}$. Information collected for every coarse woody debris piece intersected on each of three 7.32-m transects on each FIA subplot are transect diameter, length, small-end diameter, large-end diameter, decay class, and species. Transect diameter is the diameter of a down woody piece at the point of intersection with a sampling transect. Length is the length of each coarse woody debris piece between the small- and large-end diameters. Decay class is a subjective determination of the amount of decay present in an individual log. Decay class one is the least decayed (freshly fallen log), while decay class five is an extremely decayed log typically consisting of a pile of brown, cubicle rot. The species of each fallen log is identified by determining species-specific bark, branching, bud, and wood composition attributes (excluding decay class five coarse woody debris pieces) (for sample protocol details, see $[3,30,31])$.

Fine woody debris are sampled on one transect on each subplot. Fine woody debris pieces with diameters less than $2.54 \mathrm{~cm}$ were tallied separately on a $1.83-\mathrm{m}$ slope distance transect. Fine woody debris pieces with transect diameters of 2.55 to $7.59 \mathrm{~cm}$ were tallied on a $3.05-\mathrm{m}$ slope-distance transect (for more information on class definitions see [32]). Fine woody debris sampling methods on FIA plots are detailed by Woodall \& Monleon [3].

\section{Data}

Between 2001 and 2005, a total of 4,531 forest inventory plots were measured for coarse and fine woody debris by the FIA program in 45 of the continental 48 states (sampling not established in Mississippi, Wyoming, and New Mexico). Due to extreme disturbance events (e.g. tornadoes) or potential field measurement errors, $1.8 \%$ of plot observations were deemed outliers and removed from analyses (122 plots). Outlier removal protocol was based on 10 times the interquartile range such that a plot having either coarse woody debris carbon estimates $>43.7$ tonnes $\mathrm{ha}^{\wedge}-1$ or fine woody debris carbon estimates $>33.3$ tonnes $\mathrm{ha}^{\wedge}-1$ was excluded from study analyses. The field data used in this study may be accessed at [28].

The Köppen Climate Classification System, originally developed by Vldamir Köppen in 1900, is one of the most 
widely used for classifying the world's climatic regions [33-36]. Since the map's early introduction, numerous geographers have updated/modified it to the current version used in this study (United States map, see [37]). The modified Köppen classification uses three letters corresponding to average annual precipitation, average monthly precipitation, and average monthly temperature to divide the world into six major climatic regions of which only four are applicable to the conterminous United States. The first letter of the classification scheme refers to very broad climatic zones (e.g. equatorial or polar), the second letter denotes the seasonality of precipitation (e.g. summer dry or fully humid), and the third letter denotes the air temperature (e.g., hot or cool summer) (Table 3).

Six climatic variables were correlated with coarse and fine woody debris carbon stocks in this study: PRECIP, TMAX, TMIN, MOIST, VAR, and EVAP. Data for the PRECIP, TMAX, and TMIN were obtained from the Parameter-elevation Regressions on Independent Slopes Model (PRISM) dataset (4-km grid cell size; PRISM Group [38]). Each of these three variables is represented by a 30-year climate normal. As such, annual precipitation is the mean annual total precipitation from 1971 to 2000. TMAX and TMIN are the mean daily temperature extremes for that period. Emerging research has indicated that certain forest attributes, such as standing live tree biomass, may be more correlated with certain monthly minimums/maximums (e.g., minimum January temperature) [39]. However, as little research has been conducted to determine which climatic summaries are most highly correlated with forest dead wood attributes, our study utilized annual summaries as starting point.

The MOIST, VAR, and EVAP climatic variables are derived from a revised Thornthwaite global climate classification (4-km grid cell size, [35]). MOIST, an indication of water surplus or deficit, is intended to indicate vegetation water availability. EVAP is a surrogate for the thermal energy available in a given location. VAR is derived from the
MOIST variable and indicates whether seasonal variability is caused by temperature, precipitation, or a combination of both. The three variables for the revised Thornthwaite classification were derived from global temperature and precipitation datasets available from the University of Delaware Center for Climatic Research $[40,41]$.

\section{Analysis}

Coarse and fine woody debris carbon contents were estimated using a combination of line-intersect volume per unit area estimators and conversion factors for biomass and carbon [3]. Line-intersect sampling estimators were used to determine volume per unit area estimates for sample plots based on sub-plot transects. These volume per unit area estimators are simply equations to determine the volume that a given sample of coarse woody debris pieces represent for an entire area of interest. The shorter the sample transect or coarse woody debris piece the larger the volume that piece represents on a per unit area basis. Estimates of volume were first converted to biomass and then to carbon using conversion constants $[3,31,42]$. Carbon storage in coarse woody debris $\left(\mathrm{C}_{\mathrm{CWD}}\right)$ (tonnes ha^ ${ }^{\wedge}$ 1) was calculated using Eq. (1):

$$
C_{C W D}=\sum_{i=1}^{n}\left(c_{i} G_{i}\right)\left[\left(\frac{\pi}{2 L}\right)\left(\frac{V_{i}}{l_{i}}\right) f\right]
$$

where $n$ is the number of pieces, $c_{i}$ is the proportion of $C$ in the mass of the ith piece, $f$ is the conversion factor for unit-area values $(10,000), G_{i}$ is the estimated bulk density $\left(\mathrm{g} \mathrm{m}^{-3}\right)$ of the ith piece reduced by a modeled decay reduction factor, $L$ is the total length of the transect corrected for slope $(\mathrm{m}), V_{i}$ is the volume of the $i$ th coarse woody piece $\left(\mathrm{m}^{3}\right)$, and $l_{i}$ is the length of the ith piece in meters [3]. Birdsey [42] provides mean conversion factors (c) for both softwood (0.521) and hardwood species (0.491). Waddell [31] provides decay reduction factors for various coarse woody debris decay stages for reducing the specific gravity of coarse woody debris pieces based on the state of decay.

Table 3: Modified Köppen's climatic classification regions and subgroups used in this study

\begin{tabular}{cll}
\hline Climatic region & Climatic region description & Associated United States forest ecosystem/region \\
\hline BS & Arid steppe & Intermountain dry grasslands \\
BW & Arid desert & Southwestern deserts \\
Cs & Warm temperate with dry summer & Chaparral \\
Cf & Warm temperate, fully humid & Southeastern mixed forests \\
Ds & Snow with dry summer & Northern Rockies \\
Dw & Snow with dry winter & Northern Rockies \\
Dfa & Snow, fully humid, hot summer & Mid-Atlantic \\
Dfb & Snow, fully humid, warm summer & Upper midwest and northeast \\
Dfc & Snow, fully humid, cool summer & Extreme northern boreal \\
H & Highland & High elevation alpine
\end{tabular}


Carbon storage in fine woody debris $\left(\mathrm{C}_{\mathrm{FWD}}\right)$ (tonnes ha^1) was calculated using Eq. (2):

$$
C_{F W D}=\sum_{i=1}^{n} \frac{\left(G_{i} a_{i} c_{i} s k\right)}{L} t_{i} \bar{d}_{i}^{2}
$$

where $n$ is fine woody debris size class (medium or large), $G_{i}$ is the bulk density $\left(\mathrm{g} \mathrm{m}^{-3}\right)$ of the ith class, $a_{i}$ is the nonhorizontal lean angle correction factor for $i$ th class, $c_{i}$ is the proportion of carbon in the ith class, $s$ is the slope correction factor because fine woody debris is measured along a slope-distance transect, $k$ is a constant representing both unit conversion and a constant for fine woody debris piece lengths (1.234), $L$ is the slope length of the transect $(\mathrm{m}), t_{i}$ is the number of pieces of fine woody debris in the $i$ th size class, and $d_{i}$ is the mean diameter $(\mathrm{cm})$ of pieces within size class $i$. Because species data are not collected for fine woody debris, values of $G, c$, and $a$ were based on the forest type assessed during phase 2 measurements [3]. Carbon storage for the smallest fine woody debris size class $(<0.64 \mathrm{~cm})$ was not included in plot totals because this stock is included in forest floor measurements of litter.

The mean and standard errors for coarse and fine woody debris carbon stocks were estimated by Köppen climatic region/subregion. Köppen climatic subregions were collapsed into regions if sample sizes were insufficient. The significance of differences in mean coarse and fine woody debris carbon stocks between Köppen's classes was tested using an analysis of variance (ANOVA). Differences in means among climatic regions were deemed significant at the 0.05 level. To assess the relationship between coarse and fine woody debris carbon stocks and climatic variables and to elucidate dead wood trends between Köppen's classes, Pearson's correlations coefficients and associated p-values were determined and displayed in a correlation matrix. Additionally, a linear regression was conducted between the dependent variable of total woody detritus stocks and the independent climatic variables of TMAX and PRECIP.

\section{List of abbreviations}

PRECIP: average annual precipitation; TMAX: mean annual maximum temperature; TMIN: mean annual minimum temperature; MOIST: moisture index; VAR: variability cause; EVAP: potential evapotranspiration; FIA: Forest Inventory and Analysis

\section{Competing interests}

The authors declare that they have no competing interests.

\section{Authors' contributions}

CWW designed the study, conducted the majority of analyses, and wrote the manuscript, GCL acquired all meteor- ological data layers and assisted with Geographic Information System analytical operations. Additionally, GCL provided interpretations of study results. All authors read and approved the final manuscript.

\section{References}

I. Malhi Y, Baldocchi DD, Jarvis PG: The carbon balance of tropical, temperate, and boreal forests. Plant, Cell, and the Environment 1999, 22:715-740.

2. Smith JE, Heath LS, Woodbury PB: How to estimate forest carbon for large areas from inventory data. Journal of Forestry 2004, I02:25-31.

3. Woodall CW, Monleon VJ: Sampling protocol, estimation, and analysis procedures for the down woody materials indicator of the FIA program General Technical Report, NRS-GTR-22, USDA Forest Service, Newtown Square, PA; 2008.

4. U.S. Department of Agriculture, Forest Service: National report on sustainable forests - 2003 U.S. Department of Agriculture, Forest Service. FS-766. Washington, DC; 2004.

5. Yin X: The decay of forest woody debris: numerical modeling and implications based on some $\mathbf{3 0 0}$ data cases from North America. Oecologia 1999, 121:81-98.

6. Berry J, Bjorkman O: Photosynthesis response and adaptation to temperature in higher plants. Annual Review of Plant Physiology | 980, 3 I:49|-543.

7. Raich JW, Russell AE, Kitayama K, Parton WJ, Vitousek PM: Temperature influences carbon accumulation in moist tropical forests. Ecology 2006, 87:76-87.

8. Hamilton JG, DeLucia EH, George K, Naidu SL, Finzi AC, Schlesinger WH: Forest carbon balance under elevated $\mathbf{C O}_{2}$. Oecologia 2002, I 3 |:250-260.

9. Sun OJ, Campbell JC, Law BE, Wolf V: Dynamics of carbon stocks in soils and detritus across chronosequences of different forest types in the Pacific Northwest, USA. Global Change Biology 2004, 10:1470-1481.

10. Erbrecht T, Lucht W: Impacts of large-scale climatic disturbances on the terrestrial carbon cycle. Carbon Balance and Management 2006, I:7.

II. Steffen W: The Anthropocene, global change, and sleeping giants: where on Earth are we going? Carbon Balance Manag 2006, I:3.

12. Zeng N: Carbon sequestration via wood burial. Carbon Balance and Management 2008, 3:I.

13. Woodall CW, Liknes GC: Relationships between forest fine and coarse woody debris carbon stocks across latitudinal gradients in the United States as an indicator of climate change effects. Ecological Indicators 2008, 8:686-690.

14. Harmon ME: Decomposition of standing dead trees in southern Appalachian Mountains. Oecologia 1982, 52:214-2I5.

15. Harmon ME, Krankina ON, Sexton J: Decomposition vectors: a new approach to estimating woody detritus decomposition dynamics. Canadian Journal of Forest Research 2000, 30:76-84.

16. Lindroth $A$, Grelle A, Moren A: Long-term measurements of boreal forest carbon balance reveal large temperature sensitivity. Global Change Biology 1998, 4:443-450.

17. Baker TR, Honorio Coronado EN, Phillips OL, Martin J, Heijden GMF van der, Garcia M, Espejo JS: Low stocks of coarse woody debris in a southwest Amazonian forest. Oecologia 2007, 1 52:495-504.

18. Gough CM, Vogel CS, Kazanski C, Nagel L, Flower CE, Curtis PS: Coarse woody debris and the carbon balance of a north temperate forest. Forest Ecology and Management 2007, 244:60-67.

19. Simmons AJ, Fernandez IJ, Briggs RD, Delaney MT: Forest floor carbon pools and fluxes along a regional climate gradient in Maine, USA. Forest Ecology and Management 1996, 84:8I-95.

20. Iverson LR, Prasad AM: Predicting abundance of $\mathbf{8 0}$ tree species following climate change in the eastern United States. Ecological Monographs 1998, 68:465-485.

21. Bailey RG: Description of the ecoregions of the United States 2nd edition. Misc. Publ. 1391. USDA Forest Service, Washington, DC; 1995.

22. Hautala $\mathrm{H}$, Jalonen J, Laaka-Lindberg S, Vanha-Majamaa I: Impacts of retention felling on coarse woody debris (CWD) in mature boreal spruce forests in Finland. Biodiversity and Conservation 2004, I3:| $54|-| 554$. 
23. Woodall CW, Nagel LM: Down woody fuel loadings dynamics of a large-scale blowdown in northern Minnesota. Forest Ecology and Management 2007, 247:194-199.

24. Böhl J, Brändli UB: Deadwood volume assessment in the third Swiss National Forest Inventory: methods and first results. European Journal of Forest Research 2007, I 26:449-457.

25. Woodall CW, Oswalt S, Morin R: Attributes of down woody materials in eastern hardwood forests. In Proceedings, 15th Central Hardwood Forest Conference Edited by: Buckley DS, Clatterbuck WK. E-Gen. Tech. Rep. SRS-I0I. U.S. Department of Agriculture, Forest Service, Southern Research Station; 2007.

26. Dixon RK, Brown S, Houghton RA, Solomon AM, Trexler MC, Wisniewski J: Carbon pools and flux of global forest ecosystems. Science 1994, 263: 185-190.

27. Gorham E: Northern peatlands: role in the carbon cycle and probably responses to climatic warming. Ecological Applications 1991, I:182-195.

28. U.S. Department of Agriculture, Forest Service: Forest inventory and analysis datamart 2008 [http://fiatools.fs.fed.us/fiadb-downloads/ fiadb3.html].

29. Bechtold WA, Patterson PL, (eds.): The enhanced Forest Inventory and Analysis program-national sampling design and estimation procedures General Technical Report SRS-80. USDA Forest Service, Asheville, NC; 2005.

30. U.S. Department of Agriculture, Forest Service: Forest inventory and analysis national core field guide: field data collection procedures for phase 3 plots. Version 3.0. Unpublished information on file at 2005 [http://soc rates.lv-hrc.nevada.edu/fia/dab/databandindex.html].

31. Waddell KL: Sampling coarse woody debris for multiple attributes in extensive resource inventories. Ecological Indicators 2002, I: I39-153.

32. Deeming JE, Burgan RE, Cohen JD: The National Fire Danger Rating System - 1978 General Technical Report, GTR-INT-39, USDA Forest Service, Ogden, UT; 1979.

33. Köppen W: Versuch einer classification der climate, vorugsweise nach ihren beziehungen zur pflanzenwelt. Geographische Zeitschrift 1900, 6:593-61 I. 657-679.

34. Strahler AN: Elements of Physical Geography John Wiley and Sons, NY; 1984.

35. Feddema J]: A revised Thornthwaite-type global climate classification. Physical Geography 2005, 26:442-466.

36. Kottek M, Grieser J, Beck C, Rudolf B, Rubel F: World map of the Köppen-Geiger climate classification updated. Meterologische Zeitschrift 2006, 15:259-263.

37. Godfrey B: United States Köppen climate classification Ist edition. 1999 [http://snow.ag.uidaho.edu/Clim Map/koppen usa map.htm]. Idaho state climate services, University of Idaho, Moscow, ID November 2006.

38. PRISM Group: Oregon State University. [http://www.prismcli mate.org]. created $4 \mathrm{Feb} 2004$.

39. Liknes GC, Woodall CW: An evaluation of climate parameters in relation to forest inventory data: towards guidance for satellite-based forest attribute modeling. Proceedings of ForestSat 2007-Forests and Remote Sensing: Methods and Operational Tools; Nov. 5-7, 2007; Montpellier, France 2007.

40. Legates DR, Willmott C]: Mean Seasonal and Spatial Variability in Gauge-Corrected, Global Precipitation. International Journal of Climatology 1990, 10: I I - I 27.

4I. Legates DR, Willmott CJ: Mean Seasonal and Spatial Variability in Global Surface Air Temperature. Theoretical and Applied Climatology 1990, 4 I: I I-2I.

42. Birdsey RA: Carbon Storage and Accumulation in United States Forest Ecosystems General Technical Report WO-59, USDA Forest Service, Washington, DC; 1992

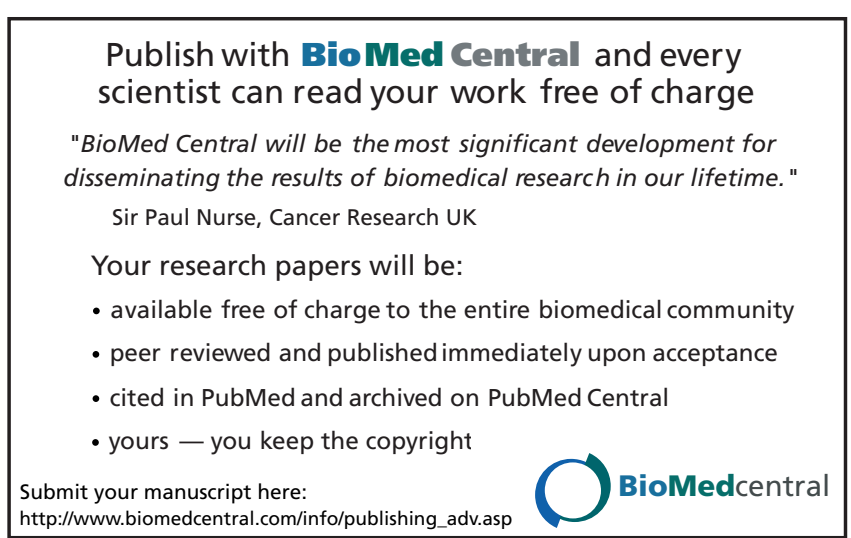

